\title{
AIRBORNE TO UAS LIDAR: AN ANALYSIS OF UAS LIDAR GROUND CONTROL TARGETS
}

\author{
L. Davidson ${ }^{1}$, J. P. Mills ${ }^{1}$, I. Haynes ${ }^{2}$, C. Augarde $^{3}$, P. Bryan ${ }^{4}$, M. Douglas ${ }^{5}$ \\ ${ }^{1}$ School of Engineering, Newcastle University, Newcastle upon Tyne, UK - (1.davidson6, jon.mills)@newcastle.ac.uk \\ ${ }^{2}$ School of History Classics and Archaeology, Newcastle University, Newcastle upon Tyne, UK - ian.haynes@newcastle.ac.uk \\ ${ }^{3}$ Department of Engineering, Durham University, Durham, UK - charles.augarde@durham.ac.uk \\ ${ }^{4}$ Historic England, 37 Tanner Row, York, UK - paul.bryan@historicengland.org.uk \\ ${ }^{5}$ English Heritage, 37 Tanner Row, York, UK - mark.douglas@english-heritage.org.uk
}

\section{Commission I/II, ICWG I/II}

KEY WORDS: drones, ground control, laser scanning, lidar, SUA targets, UAS, UAV

\begin{abstract}
:
Creating accurate models of the Earth's surface is an essential step when analysing geomorphological changes through time. Alongside photogrammetry, airborne lidar is an established method for measuring and modelling the Earth's surface. However, improvements in size, weight and power requirements mean that lidar is now increasingly capable of being operated from Unpiloted Aircraft Systems (UASs). While academic literature is currently weighted towards issues associated with airborne laser scanning, UASs operate under different parameters to piloted aeroplanes and helicopters. In order to achieve desired results from UAS lidar, mission planning parameters and ground control requirements therefore need to be tailored to data collection from UAS platforms. This paper presents the preliminary results of how a variety control target designs responded to a UAS lidar survey flown along different trajectories at different heights above ground level. This research draws upon previous airborne laser scanning work and aims to provide guidance on considerations for UAS lidar specific ground control targets.
\end{abstract}

\section{INTRODUCTION}

Unpiloted Aircraft Systems (UASs) operate under different parameters to aeroplanes and helicopters, such as a shorter operating times, lower flying heights, a decrease in velocity and enhanced manoeuvrability. As a result, point densities arising from UAS lidar (light detection and ranging) survey generally greatly exceed those of airborne lidar providing ultra-high resolution 3D point clouds of complex environments. (Mandlburger, 2015). For example, The ROBIN MINI +UAV LiDAR system (subsequently referred to as "Robin Mini") at a $50 \mathrm{~m}$ range produces 62 points per $\mathrm{m}^{2}$ when flown at a speed of $5 \mathrm{~ms}^{-1}$ (3D Laser Mapping, 2018). With a high degree of overlapping flight strips and multiple returns per pulse, this figure can be greatly exceeded. Glira et al (2015) achieved a mean laser pulse density of 1500 points per $\mathrm{m}^{2}$ with a flying height of 25 to $50 \mathrm{~m}$ above ground level (AGL), a flying speed of $8 \mathrm{~ms}^{-1}$ and a $40 \mathrm{~m}$ strip separation. This was over a wooded area and includes returns from trees, other vegetation and the ground. While UAS lidar has seen improvements in recent years and has experienced an uptake in use for generating high resolution digital elevation models, their light-weight component parts do not provide survey grade solutions and are therefore less accurate (Bakuła et al., 2017). However, high accuracies can be achieved through the use of ground control and post-processing: Bakuła et al. (2017) saw an improvement of several $\mathrm{cm}$ in UAS lidar data, collected for the purpose of levee monitoring, when using ground control points. Much of the literature regarding lidar specific ground control targets comes from airborne lidar (see Casanyi and Toth (2007); Toth et al. (2008); Canavoslo-Zuzeiski et al. (2013)). Cramer et al. (2018) employed targets designed specifically for use in UAS lidar surveys to determine absolute orientation of the lidar point cloud in their research on ultra-high precision UAS-based lidar and dense image matching.
Due to the differences between airborne and UAS lidar, and an increase in the usage of UAS lidar, this paper seeks to determine optimised specific ground control targets for UAS lidar surveys. Section 2 discusses the background to the research. Section 3 focuses on the methodology, including the calibration of the UAS lidar system, a description of the targets tested, mission planning and fieldwork, and a description of the equipment employed. Section 4 presents the results of the research. The paper concludes with a discussion and conclusion provided by Sections 5 and 6 , respectively.

\section{BACKGROUND}

Advancements in remote sensing platforms and sensors is occurring at an unprecedented rate. The growth of UASs, and in particular Small Unpiloted Aircraft (SUA), weighing $20 \mathrm{~kg}$ or less, as defined by the Civil Aviation Authority, UK (Civil Avaiation Authority, 2019), combined with developments in sensor technology and data information processing, has led to an increase in accessibility in this technology and what it has to offer to both scientific research and industrial applications (Toth and Jóźków, 2016). Over the past twenty years, lidar has undergone major technological developments and has become increasingly more affordable (Toth and Jóźków, 2016), with units seeing significant improvements with regards to size, weight and power (SWaP) requirements. Lidar systems have conventionally been mounted in airborne platforms, such as fixed wing aeroplanes or rotating wing helicopters, and required expensive specialist equipment and software, a pilot and flight crew. Today there are a variety of systems suited to different platforms, ranging from satellite to terrestrial platforms (Toth and Jóźków, 2016), and including commercial UASs capable of carrying specifically adapted lightweight lidar systems (Pajares, 2015). 
A typical UAS lidar system consists of a laser scanner, an Inertial Measurement Unit (IMU), Global Navigation Satellite System (GNSS), a power source and an on-board computer (Pilarska et al., 2016). The scanner provides the ranging data, the IMU measures variations in attitude, and the GNSS receivers provides positioning information and time synchronisation between the sensors. When integrated together, these multi-sensor systems therefore provide the precision necessary for a direct georeferencing solution (Pilarska et al., 2016). However, the resulting point clouds produced from UAS lidar systems, like those produced from standard airborne lidar, can contain errors that need to be corrected and accounted for (Pilarska et al, 2016).

In order to become widely accepted by the professional mapping community, it is essential that UAS lidar data complies with the required standards set out, for example by the American Society for Photogrammetry and Remote Sensing (ASPRS), regarding positional accuracy of digital geospatial data (ASPRS, 2015). If UAS lidar data is to meet the thresholds for digital planimetric and digital elevation data then the sources of error within UAS lidar need to be carefully considered. These are likely to be similar to those of airborne lidar (Pilarska et al., 2016), which can largely be attributed to positional error from GNSS, attitude error from the IMU and ranging error from the laser rangefinder (ASPRS, 2015). However, due to major differences existing between airborne and UAS lidar (e.g. size, weight, flying altitude, flying speeds and enhanced manoeuvrability), the final measurement accuracy of the UAS derived point cloud should be evaluated.

Systematic errors can be identified in point clouds as mismatches between flight lines. While a number of strip adjustment methods exist to calibrate and correct for these errors, they rely on features characterised by smooth rolling surfaces with surface normals in three directions (Csanyi and Toth, 2007). Roofs of buildings generally serve this requirement (Csanyi and Toth, 2007), however natural or rural areas often do not include features which fulfil this constraint. Furthermore, these methods of alignment improve the relative accuracy of the digital spatial data but do not provide an absolute accuracy assessment. Implementing ground control ensures that the UAS point cloud is accurately registered to the horizontal and vertical datums (Federal Emergency Management Agency, 2003). Using lidar specific targets may have the potential to overcome the lack of suitable features in natural and rural landscapes and also provide an assessment of absolute accuracy (Csanyi and Toth, 2007).

Csanyi and Toth (2007) proposed the use of lidar specific ground targets for airborne lidar missions. Based on simulations and field experiments, it was concluded that the optimal lidar specific ground target design for a point density of 5 points per $\mathrm{m}^{2}$ is rotation invariant, circular, elevated from the ground and has a radius of $1 \mathrm{~m}$. In addition, it was recommended to cover the surface of the target with coatings that have a high contrast in reflectance properties. These experiments were later followed by tests using road pavement markings as ground control (Toth et al., 2008). While this method proved to be faster in terms of the ground control survey (i.e. physical lidar specific ground targets did not need to be laid out), the intensity values were found not to be uniform across the markings, making them difficult to identify (Toth et al., 2008). Moreover, road pavement markings are generally unavailable in rural and natural environments.
Canavosio-Zuzelski et al. (2013) offered alternative airborne lidar specific ground targets to that originally proposed by Csanyi and Toth in 2007. Their Hexagonal Retro-Reflective lidar ground Target (HRRT) was designed to minimise obstruction of the ground by mounting retro-reflectors to the end of six arms configured in a hexagonal shape and elevated from the ground. This design allowed for more ground returns in the location of the HRRT. It also had the added benefit of a decrease in required point density (c. 2 points per $\mathrm{m}^{2}$ ) for identification (Canavosio-Zuzelski et al., 2013). Research regarding targets specific to UAS lidar survey is lacking. However, Cramer et al. (2018) have employed lidar specific targets to provide absolute orientation for research concerning ultra-high precision UAS-based lidar and dense image matching. These targets were 'gable roof' shaped.

\section{METHODOLOGY}

\subsection{Sensor calibration}

Calibration of a SUA-mounted Robin Mini was undertaken at Nafferton Farm, Stocksfield, UK on 19 February, 2019. The equipment was flown at $40 \mathrm{~m}$ and $60 \mathrm{~m}$ AGL over a farm building with a gabled roof, both along the length of the ridges and at 90 degrees to them. The data was initially processed in MMProcess v. 17.10.0.0, SBG Systems Post Processing Exporter v. 1.2.3791, and Way Point Inertial Explorer v. 8.70. The output, the trajectory data and the point cloud, from this initial step was further analysed and processed in Terrasolid (within Microstation) software using TerraScan and TerraMatch. Corrections were applied to the roll, pitch, yaw and mirror scale, minimizing the mismatch (Figure 1) by aligning the strips (Figure 2). These values were then used during the processing workflow from subsequent flights.

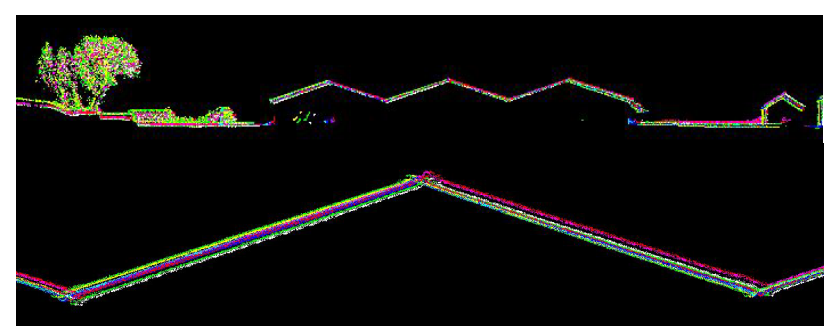

Figure 1. Strip alignment prior to corrections.

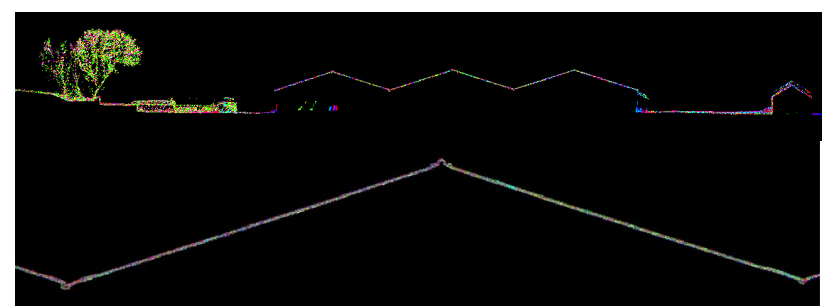

Figure 2. Strip alignment after application of roll, pitch, yaw and mirror scale shift corrections applied.

\subsection{Targets}

Seven targets of varying size, geometry and material were constructed in order to test their response to the Robin Mini and assess their suitability for providing ground control for future SUA lidar surveys with the Robin Mini (Figure 3). These included Targets 1 to 4 (T1, T2, T3 and T4) which were of identical construction and were based on the 'gable roof' shaped targets employed by Cramer et al. (2018) These four 
targets were constructed of three pieces of wood: two pieces, measuring 0.80 by $0.40 \mathrm{~m}$, affixed together at a 90 degree angle; the third piece providing a base for the 'gable roof' structure and thereby allowing it to be mounted to a tripod. For each target, a retroreflective mini target was adhered to each of the four corners on both sides of the 'gabled roof'.

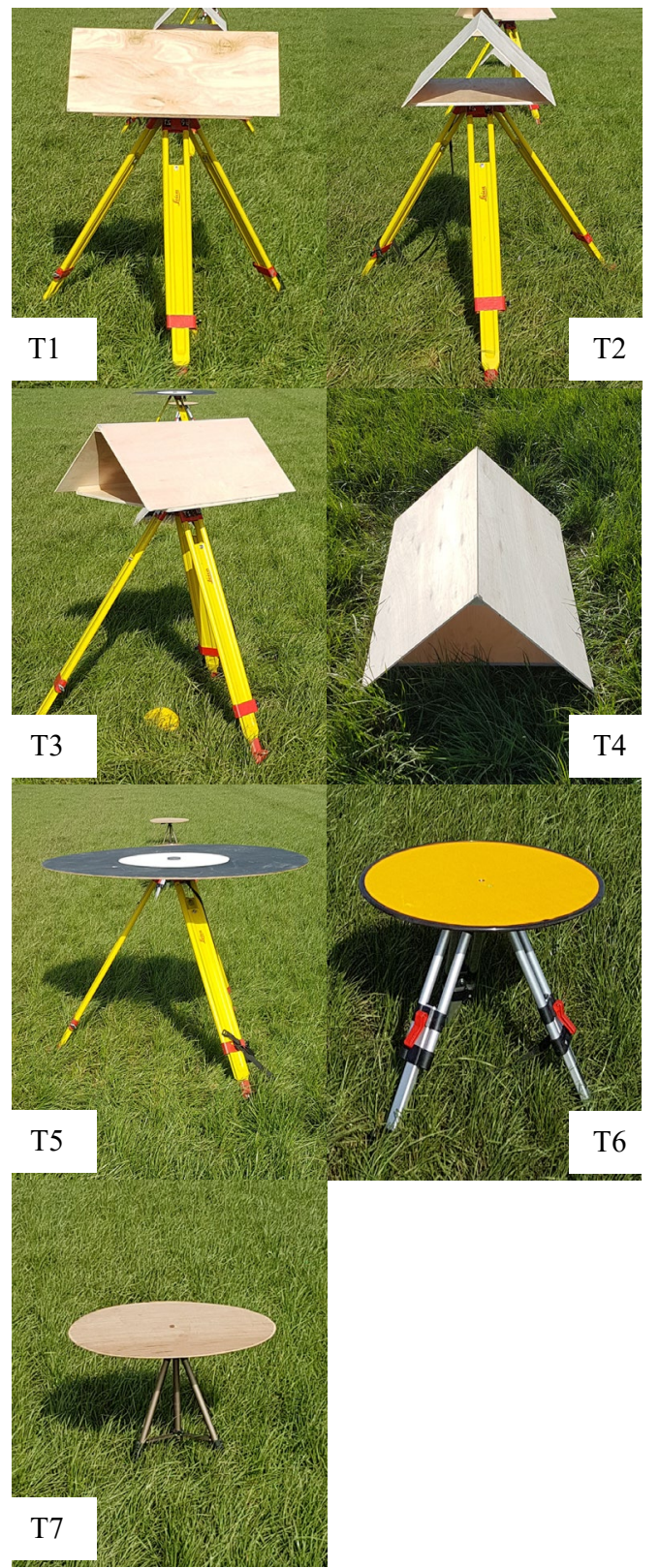

Figure 3. Targets T1 to T7 located in the survey area, looking north-east.

Target 5 (T5) was constructed of a circular piece of plywood measuring $1.20 \mathrm{~m}$ in diameter. This target was coated in black and white matt paint with two concentric circles, an inner circle, painted white and measuring $0.50 \mathrm{~m}$ in diameter, the remaining outer $0.70 \mathrm{~m}$ wide concentric ring was painted black. A small hole was cut in the centre of the target and a bespoke bracket placed inside in order for it to be mounted to a survey tripod. This target was originally employed by Lim et al. (2007) for a helicopter-borne lidar survey and was designed according to the findings of the research undertaken by Csanyi and Toth (2007) on lidar-specific ground targets. Target 6 (T6) was a reflective ground target which was designed for, and is delivered with, the SUA LidarPod sensor manufactured by Routescene (Routescene, 2019). It was $0.60 \mathrm{~m}$ in diameter and made of retroreflective traffic sign material with a rubber protective guard around its perimeter. This reflective ground target was equipped with a spirit level and a bracket which enabled it to be levelled and mounted to a mini survey tripod. Target 7 (T7) was also $0.60 \mathrm{~m}$ in diameter. However it was made of plywood, with no reflective coating, and was mounted to a camera tripod. This provided a cheaper alternative to the industrial target produced by Routescene.

\subsection{Mission planning}

Mission planning was undertaken in QGIS 2.18.6. Shapefiles representing target location and flight paths were created using the Ordnance Survey Great Britain 1936 (OSGB36) coordinate system. The target coordinates were extracted from QGIS and were manually input into a Leica GS18 GNSS controller for stakeout. Four flight paths, each with a different flying height, at $20 \mathrm{~m}$ (Flight 1), $40 \mathrm{~m}$ (Flight 2), $60 \mathrm{~m}$ (Flight 3) and $80 \mathrm{~m}$ (Flight 4) AGL, were created following three parallel lines, one directly over the linear array of targets (Strip 1) and one offset either side of the targets (Strips 2 and 3). The purpose of flying multiple strips was to record the targets' response to near-nadir and off-nadir scan angles at different ranges. Flight line separation was based on a $50 \%$ side overlap with a field of view of 60 degrees, resulting in a nominal separation of $11.5 \mathrm{~m}$ (Flight 1), $23 \mathrm{~m}$ (Flight 2), $34.5 \mathrm{~m}$ (Flight 3) and $46.2 \mathrm{~m}$ (Flight 4). A fourth parallel flight line and two cross-track flight lines were also included in each of the flight plans in order to collect data for flight line alignment in the instance where any mismatch between flight lines was observed. However, due to the homogeneity of the field in which the targets were recorded, strip alignment proved not to be possible. The flight path files were exported as KML files (which uses WGS84 coordinates) which were then uploaded to DJI GS Pro app. Way points of the flight paths were edited to follow a curved route while turning. These flight paths allowed the SUA to follow the predetermined flight routes in autonomous mode.

For further details regarding flight parameters see Table 1.

\begin{tabular}{|c|c|c|c|c|}
\hline Parameter & $\begin{array}{c}\text { Flight } \\
1\end{array}$ & $\begin{array}{c}\text { Flight } \\
2\end{array}$ & $\begin{array}{c}\text { Flight } \\
3\end{array}$ & $\begin{array}{c}\text { Flight } \\
4\end{array}$ \\
\hline Scan frequency $(\mathrm{Hz})$ & 100 & 100 & 100 & 100 \\
\hline Scan half-angle $\left(^{\circ}\right)$ & 30 & 30 & 30 & 30 \\
\hline $\begin{array}{l}\text { Pulse repetition } \mathrm{f} \\
(\mathrm{kHz})\end{array}$ & 100 & 100 & 100 & 100 \\
\hline $\begin{array}{l}\text { Operating Altitude } \\
\text { (m) }\end{array}$ & 20 & 40 & 60 & 80 \\
\hline Aircraft speed $\left(\mathrm{ms}^{-1}\right)$ & 5 & 5 & 5 & 5 \\
\hline $\begin{array}{l}\text { Swath width (m) } \\
\text { Flight strip } \\
\text { separation with } 50 \% \\
\text { overlap (m) }\end{array}$ & 11.5 & 46 & 34.5 & 92 \\
\hline
\end{tabular}

Table 1. Parameters of all four flights.

\subsection{Fieldwork}

A SUA lidar survey of the targets was undertaken on 23 March 2019 at Cockle Park Farm, Morpeth, UK. It was a dry day with a mixture of sun and cloud and an average wind speed between 5 and $7 \mathrm{~ms}^{-1}$. Locations for the seven targets were extracted 
from QGIS 2.18.6 in OSGB36 coordinates. The target coordinate locations were staked-out in an arable field, with low grass cover, using a Leica GS18 RTK Rover GNSS system. The targets were laid out in a straight line with $5 \mathrm{~m}$ spacing between them (Figure 4). Targets T1, T2, T3 and T5 were placed on survey tripods and levelled, the purpose of which was to raise them from the ground surface by approximately $1 \mathrm{~m}$. Target T4 was placed directly on the ground surface and Targets $\mathrm{T} 6$ and $\mathrm{T} 7$ were mounted on small tripods and levelled. These targets were raised approximately $0.5 \mathrm{~m}$ from the ground surface. Target T1 was oriented with its long axis 90 degrees to the primary flight line. Targets $\mathrm{T} 2$ and $\mathrm{T} 4$ were oriented in-line with the primary flight line and target $\mathrm{T} 3$ was oriented approximately 45 degrees to the primary flight line. Targets T5, $\mathrm{T} 6$ and $\mathrm{T} 7$ were all rotation invariant and therefore did not require aligning. The centre points of Targets T5-T7 were recorded with the Leica GS18 RTK Rover. Targets T1-T4 were marked with eight retroreflective (four on each side) selfadhesive $20 \mathrm{~mm}$ targets. These were recorded using a Leica FlexLine TS07 total station, operating in reflectorless EDM mode. Control for the total station survey was provided by four stations for which coordinates were derived using the GS18 RTK Rover. All points were recorded using the OSGB36 coordinate system.

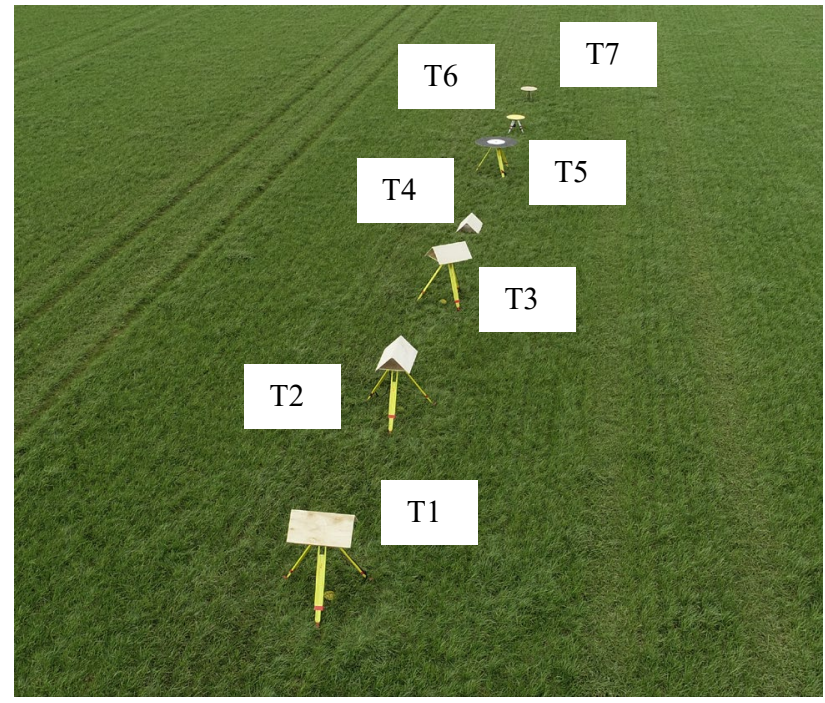

Figure 4 . Targets $\mathrm{T} 1$ to $\mathrm{T} 7$, placed linearly at $5 \mathrm{~m}$ intervals.

\subsection{Laser scanning equipment}

Data was collected using a Robin Mini mounted to a DJI Matrice 600 Pro SUA (Figure 5). The Matrice 600 Pro is a multi-rotor commercial SUA capable of carrying the Robin Mini payload, which complies with Civil Aviation Authority's 0-20kg (SUA) class regulations. The Robin Mini comprises a Riegl miniVUX-1UAV survey-grade class 1 laser scanner, a dual antenna micro-electromechanical (MEMS) IMU and two Harxon Helix GNSS antennas. This system has been specifically designed for SUA use. For RobinMini and Matrice 600 Pro specifications see Tables 2 and 3.

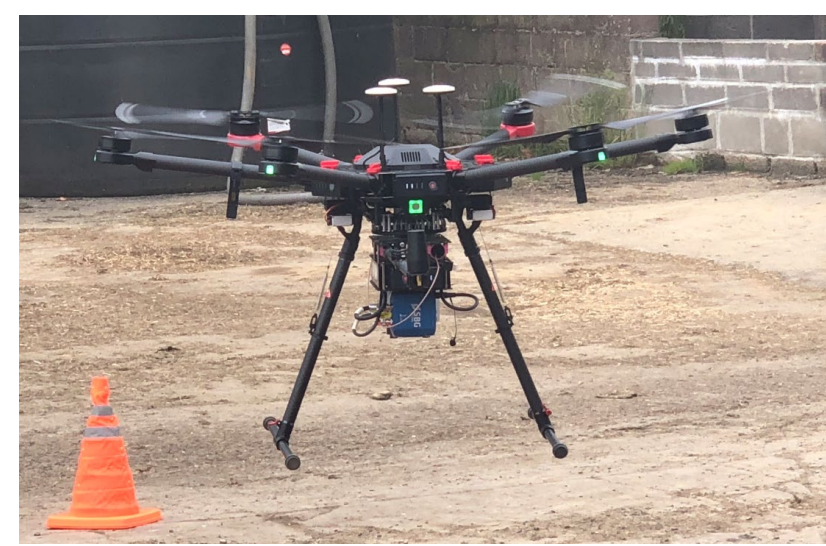

Figure 5. The Matrice 600 Pro SUA carrying the Robin Mini.

\begin{tabular}{|l|l|}
\hline Parameter & Value \\
\hline Weight (including batteries) & $10 \mathrm{~kg}$ \\
Max take-off weight & $15.5 \mathrm{~kg}$ \\
Hovering accuracy (in P-GPS & $+/-0.5 \mathrm{~m}$ vertical; +/- 1.5 m \\
mode) & horizontal \\
Hovering time with batteries & 18 minutes \\
and a 5.5 kg payload & \\
\hline
\end{tabular}

Table 2. Matrice 600 Pro Specifications (DJI, 2019)

\begin{tabular}{|l|l|}
\hline Parameter & Value \\
\hline System weight & $3.1-4.8 \mathrm{~kg}$ \\
Laser scanner & miniVUX-1UAV \\
Inertial Navigation System & $\begin{array}{l}\text { Dual Antenna Micro- } \\
\text { electromechanical (MEMS) }\end{array}$ \\
& IMU \\
GNSS & Harxon Helix Antenna x2 \\
Minimum range* & $3 \mathrm{~m}$ \\
Accuracy* & $15 \mathrm{~mm}$ \\
Precision & $10 \mathrm{~mm}$ \\
Pulse repetition rate* & $100 \mathrm{kHz}$ \\
Max effective measurement & Up to \\
rate* & 100000 measures/second \\
Scanning speed (user & $10-100$ rev/second \\
defined)* & \\
Field of view* & Up to $360^{\circ}$ \\
Echo signal intensity* & High-resolution 16 bit \\
& intensity information \\
Laser wavelength* & Near infrared \\
Laser beam divergence* & $1.6 \mathrm{x} 0.5 \mathrm{mrad}$ \\
Laser beam footprint at $100 \mathrm{~m}$ & $160 \mathrm{x} 50 \mathrm{~mm}$ \\
range* & \\
Scanning mechanism* & Rotating mirror \\
Angular step width $\Delta \partial^{*}$ & $0.05^{\circ} \leq \Delta \geq 0.5^{\circ}$ \\
Angle measurement & $0.001^{\circ}$ \\
resolution* & \\
Position** & $0.02 \mathrm{~m}$ \\
Velocity** & $0.005 \mathrm{~ms}{ }^{-1}$ \\
Roll/Pitch** & $0.02^{\circ}$ \\
Data rate** & $200 \mathrm{~Hz}$ \\
Gyro-bias** & $0.5^{\circ} / \mathrm{hour}$ \\
Gyro-RW** & $0.014^{\circ} / \sqrt{\mathrm{h}}$ \\
\hline
\end{tabular}

Table 3. Robin Mini specifications. *Mini VUX1-UAV, **MEMS IMU (3D Laser Mapping, 2018; RIEGL Laser Measurement Systems, 2018). 


\subsection{SUA lidar survey}

Prior to undertaking the SUA flight missions, a Leica GS18 GNSS base station was established in the south east corner of the field and collected continuous raw GNSS observations for three hours. This data, after post-processing in Leica Infinity v. 2.4.1.2955, was then used in the processing workflow in order to enable an accurate solution for the trajectory data.

Each of the four flights followed the same procedure. The Robin Mini was powered up, and a new IMU session was activated. After leaving the system static for two minutes to allow the IMU to warm-up, the Matrice 600 Pro carrying the Robin Mini was then flown manually in a figure-of-eight pattern for five minutes and then grounded to check the IMU status. Once IMU alignment had been confirmed, the scanner was set to record and the SUA was flown in autonomous flight mode at a velocity of $5 \mathrm{~ms}^{-1}$ following the pre-determined flight route in DJI's GS Pro app. Upon completion of the flight, the SUA was landed and the scanner switched off. It was then flown in manual mode for another five minutes in a figure-ofeight pattern to facilitate both forward and backward processing of the trajectories.

\section{PROCESSING}

Processing the data consisted of five main steps which are summarised in Figure 6.

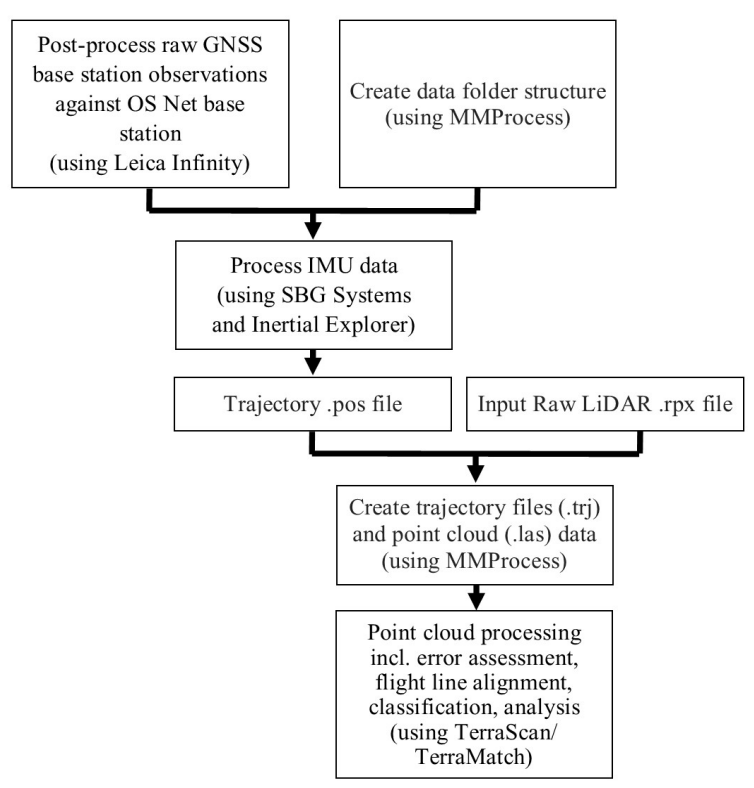

Figure 6. Data processing workflow.

\section{ANALYSIS}

The returns from Strips 1, 2, and 3 (Figure 7) were analysed in isolation and as a whole for each of the four flights. The following parameters were assessed:

- Target geometry based on total number of returns per flight and per strip;

- Target identification through elevation above ground level;

- Target identification through intensity values.

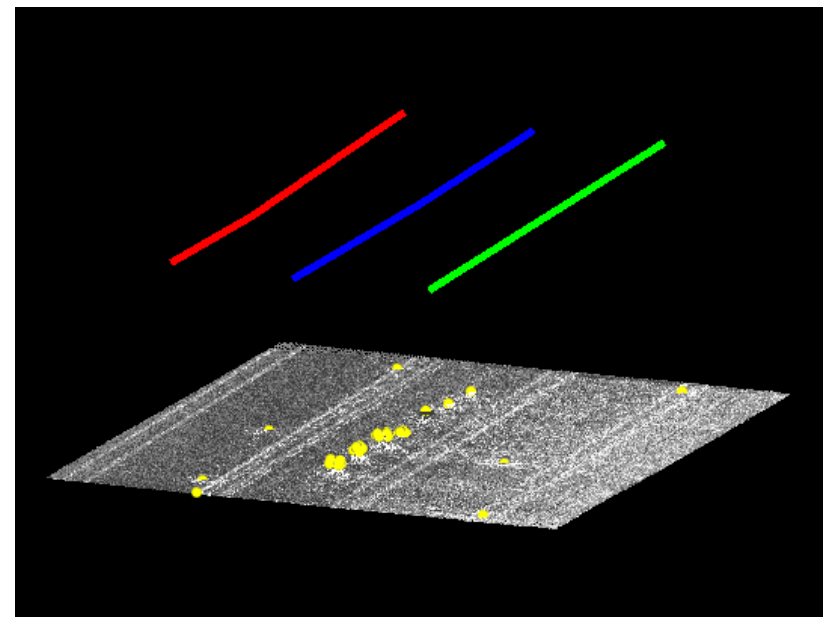

Figure 7. Point cloud from Flight 1, GNSS and total station survey. Blue: Strip 1; green: Strip 2; red: Strip 3; yellow control stations, total station set-ups and target locations.

\section{RESULTS}

\subsection{Target geometry}

The number or returns from each flight were quantified in total and on a strip wise basis. The purpose of examining the number of returns per strip was to determine the response from the targets from near-nadir and off-nadir positions in order to assess whether or not their geometry could be reconstructed. Reconstructing target geometry enables comparison of the location of the scanned target to that recorded by the GNSS/total station equipment.

Table 4 depicts returns for each of the targets per strip from Flights 1 and 4. All seven targets responded best to the parameters of Flight 1, Strip 1. The returns from the near-nadir scan angle spread across the targets surfaces in fairly uniform patterns. Multiple scan lines and a high number of returns, combined with the known shape and size of the targets, made it possible to polygonise target extents and thereby identify the central points for targets T5 - T7 and the corners for targets T1 T4. Being able to identify these key points enabled a comparison and adjustment between the target positions as recorded in the point cloud to the location ascertained using survey grade GNSS and total station equipment. This identification is important to ensure absolute accuracy and for validation purposes. T1 - T7 were all suitable for use when flying parameters match those of Flight 1 Strip 1 (low flying height, and sensor positioned directly over the targets). Returns for the off-nadir scan angles of Flight 1, Strips 2 and 3 produced less optimal coverage across targets $\mathrm{T} 1-\mathrm{T} 4$. Returns were mainly concentrated to the surface of the 'gable roof' which faced the scanner. In one instance, T1, the returns from Flight 1 Strip 2 were entirely from the north-east facing surface of the 'gable roof'

As the flying height increased, the number of scan lines crossing the targets and therefore the number of returns decreased, resulting in poorer target identification. While all targets could still be identified in Flights 2, 3 and 4, this was with increasingly less confidence. In regards to the 'gable roof' targets, the position of $\mathrm{T} 1$, orientated at $90^{\circ}$ provided the best results from the four flights. However, as the noise in the data 
increased at the higher flying heights, T1-T4 geometry deteriorated. Larger 'gable roofs' would have performed better under the parameters of Flights 3 and 4.

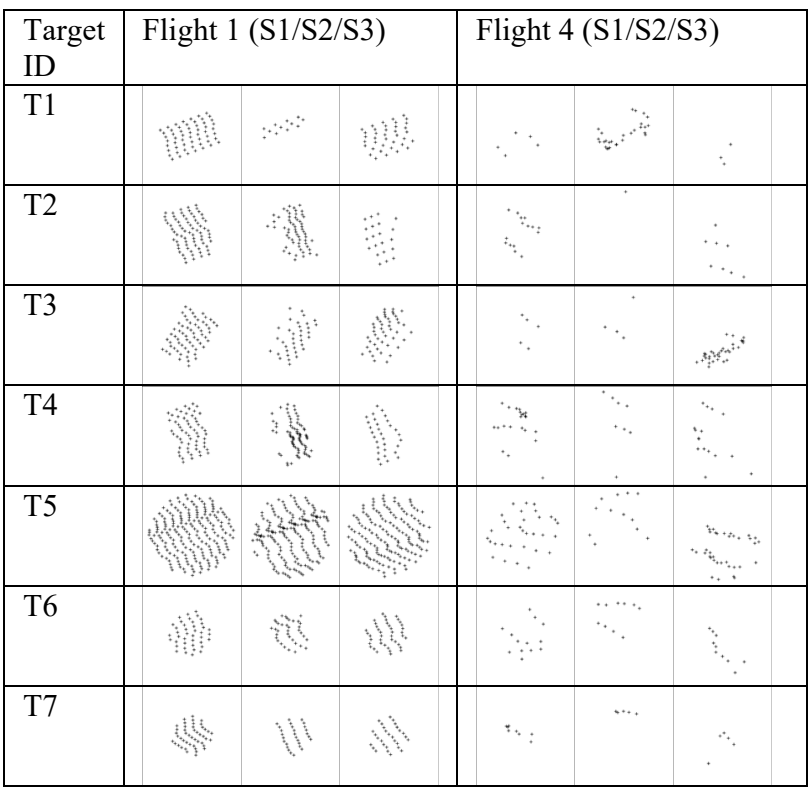

Table 4. Returns from all Targets per Strip for Flights 1 and 4

The smooth surface of the 'gabled roof' targets appeared to be roughest in Flights 3 and 4 and was smoothest in Flight 1. The near-nadir scan angle of Strip 1 provided the best coverage of these 'gable roof' targets in all flights.

All targets benefited from being recorded by multiple scan lines. However, T5, due to its size, being $1.2 \mathrm{~m}$ in diameter meant that more scan lines crossed its surface, producing a high number of returns at all four flights, even when reduced by an increase in flying height. It was possible to reconstruct the geometry of target T5 from Flight 4, Strip 1 (near-nadir scan angles). All other targets required returns from multiple strips to reconstruct their geometry from those recorded during Flight 4.

\subsection{Identification through intensity values}

Targets T1 - T4 and T7 intensity values were similar to those of the surrounding area. However, with a priori knowledge of target location (from the GNSS RTK survey), targets T1 - T4 and T7 could be identified when viewing the point cloud displayed by intensity.

Target T5, characterised by black and white concentric circles (Figure 8), resulted in a high contrast in reflectance values between the two circles. This contrast, in combination with its large size, made it the most visible of all targets in the point cloud. The contrasting painted surface could not only be easily identified in the intensity values of the returns when considering the target itself, but also against the ground surface as the outer black concentric ring intensity values were in high contrast to those of the ground surface.

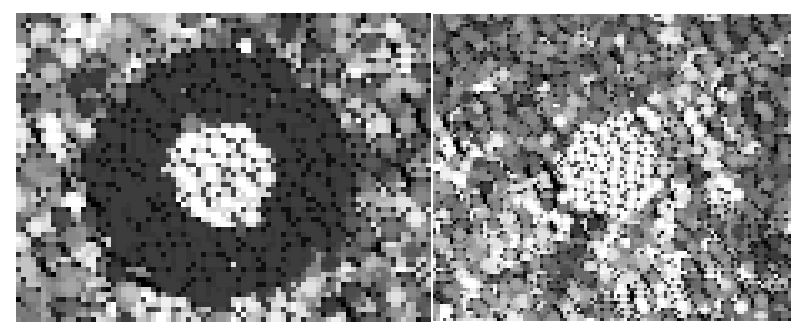

Figure 8. Target T5 (left) and T6 (right) in Flight 1 with point cloud displayed by intensity.

The intensity values from the returns of T6 (Figure 8), made of retroreflective material, were the same across the surface of the target for all flights. This made it advantageous in classification as this could be achieved using the "classify by intensity" routine in TerraScan. However, there was a number of misclassified returns from all flights due to backscatter in the data (Figure 9).

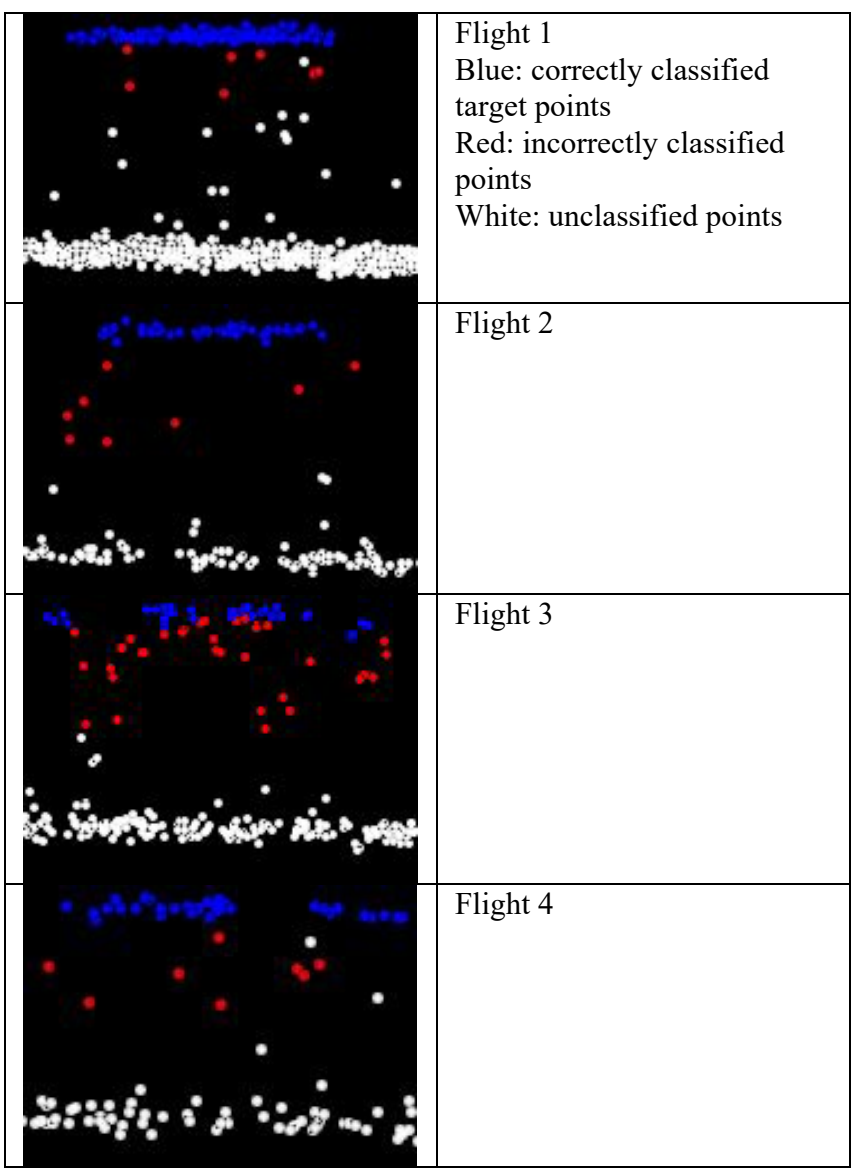

Figure 9. Point cloud for Target T6, blue and red points classified according to TerraScan's "classify by intensity" routine.

\subsection{Identification through elevation above ground level}

All targets, regardless of material, shape, size or height above ground could be identified by elevation properties in Flight 1, Strip 1. This included target T4 which despite being placed on the ground surface was visible in elevation due to its 3D geometry, particularly, the 'gable roof'. However, during flights 3 and 4, which were undertaken at higher elevations, the data became noisy and the strip misalignment became greater. This 
led to the geometry of the 'gable roof' targets T1 - T4 being less well defined (Figure 10).

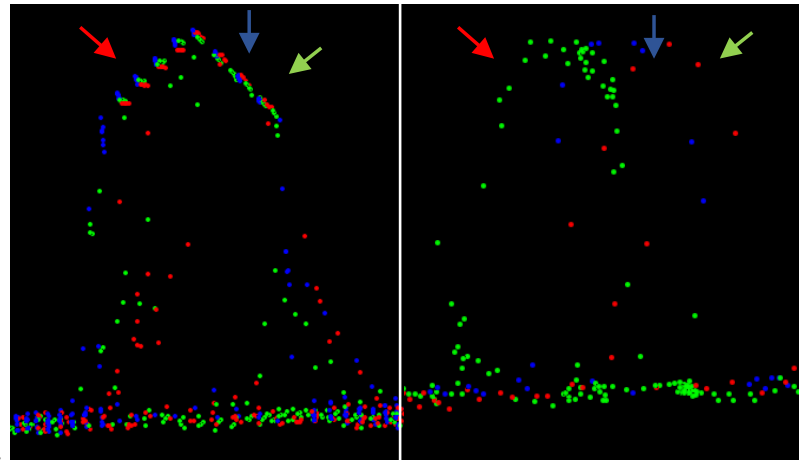

Figure 10. Point cloud for Target T1, showing strip alignment noise in Flight 1(left) and Flight 4 (right); blue: Strip 1; Green: Strip 2; and red: Strip 3. (Arrows marks angle of incidence per strip).

Some returns were misclassified for all targets which were manually edited to the correct classification. These included backscatter returns from both the tripods and the target. In addition, as the flying height increased the resulting point cloud became increasingly less structured. It was difficult to be confident in target geometry and therefore classifying targets by elevation became irrelevant. Figure 10 shows Target T1 in elevation from Flight 1 and Flight 4 . Note the level of noise and the discrepancy in strip alignment between the two flights.

\section{DISCUSSION}

While the equipment had been calibrated prior to the fieldwork being undertaken, some strip mismatch was observed in the data from all four flights. This was most prominent for the data collected during Flight 4 and minimal between strips of Flight 1. The gabled roof targets (targets $\mathrm{T} 1-\mathrm{T} 4$ ) had the benefit over the rotation invariant targets (targets $\mathrm{T} 5-\mathrm{T} 7$ ) of enabling a quick visual analysis and measurement of the mismatch. Successful strip adjustment may have reduced the noise in Flights 3 and 4, potentially improving results, however, due to the homogeneity of the area recorded, strip alignment was not possible.

Flight planning is an essential step of any UAS lidar survey. In order to maximise the returns from targets it is worth considering selecting their location in advance and setting them out with GNSS RTK equipment. Situating targets in locations where near-nadir returns are recoded or where returns are obtained from multiple strips in order to provide better coverage across the targets. However, as setting-out the targets is the most time consuming step of a UAS lidar ground survey, selecting targets fit for purpose is ideal. If flying at a low height with a higher point density, then small circular targets are optimal as they are more manageable to transport, carry, erect and record. However, if flying in a homogeneous location with a lack of human made or natural features with specific characteristics for strip adjustment, then 'gabled roof' targets (Targets T1 - T4) may be a beneficial addition in order to identify and potentially correct any strip mismatch. However, more research needs to be undertaken in regards to size, quantity and distribution of this type of target in order to perform such adjustment.

\section{CONCLUSIONS}

The following summarizes the key findings of this research to date.

- The position of targets in relation to the scanner matters. Positioning a target directly under the flight path where it will be recorded by near-nadir scan angles will give optimal results.

- The size of targets matters. A higher flying height with a lower point density will require a larger target. A target which is $0.60 \mathrm{~m}$ in diameter or which matches the specifications of the 'gabled roof' targets should fulfill the requirements when flying at lower levels such as 20 or $40 \mathrm{~m}$ at $5 \mathrm{~ms}^{-1}$ (if placed at directly under the flight path). However, at 60 or $80 \mathrm{~m}\left(5 \mathrm{~ms}^{-1}\right)$, target size should be increased proportionately. In this research, $1.2 \mathrm{~m}$ was sufficient at these flying heights when placed directly under the flight path.

- Circular targets were easier and faster to set out and subsequently record.

- Targets recorded by multiple strips increase the number or scan lines across the target and the number of returns. This is important when the target is recorded by off-nadir scan angles.

- Coating targets in high contrast paint, such as the black and white concentric rings of target $\mathrm{T} 5$, or retroreflective material, can facility quick identification of targets when viewing by intensity. The retroreflective material of Target T6 had the added benefit of producing returns with consistent intensity values across its surface, making it ideal for classification using a semi-automatic intensity routine offered in TerraScan.

- Raising targets from the ground allowed for them to be identified easily and classified using a semiautomatic height from ground routine offered in TerraScan.

- The 'gabled roof' targets allowed for strip misalignment to be identified visually in a homogenous landscape. This was less prominent with the rotation invariant targets.

When considering optimal lidar specific ground control targets for the purpose of improving the accuracy of the resulting digital elevation model and for quality assurance purposes, the above findings should be taken into consideration.

\section{ACKNOWLEDGEMENTS}

This research was supported by a NERC IAPETUS Doctoral Training Partnership award (IAP-16-96) to Lesley Davidson, with equipment provided by UKCRIC - UK Collaboratorium for Research in Infrastructure \& Cities: Newcastle Laboratories (EPSRC award EP/R010102/1).

Gottfried Mandlburger, of TU Wien and University of Stuttgart, is acknowledged for supplying details of the 'gabled roof' targets. Thanks are due to Nafferton and Cockle Park Farms, both owned by Newcastle University, for allowing the calibration flight and fieldwork to be undertaken on their 
property. Thanks are also due to David Dick for target construction and Nicky Garland, James Goodyear and Martin Robertson for assistance with fieldwork.

\section{REFERENCES}

3D Laser Mapping, 2018. ROBIN MINI + UAV. https://www.3dlasermapping.com/wpcontent/uploads/2018/01/ROBIN-MINI-Datasheet17-18WEB.pdf (29 March 2019).

ASPRS, 2015. ASPRS Positional Accuracy Standards for Digital Geospatial Data. Edition 1, Version 1.0. Photogrammetric Engineering and Remote Sensing, 81(3), A1A26.

Bakuła, K., Salch, A., Wziątek, D.Z., Ostrowski, W., Górski, K., Kurczyński, Z., 2017. Evaluation of the accuracy of lidar data acquired using a UAS for level monitoring: preliminary results. International Journal of Remote Sensing, 38, (8 - 10), 2921-2937.

Canavosio-Zuzelski, R., Hogarty, J., Rodarmel, C., Lee, M., Braun, A., 2013. Assessing Lidar Accuracy with Hexagonal Retro-Reflective Targets. Photogrammetric Engineering and Remote Sensing, 79(7), 663-670.

Civil Aviation Authority, 2019. Regulations relating to the commercial use of small drones. https://www.caa.co.uk/Commercial-

industry/Aircraft/Unmanned-aircraft/Small-drones/Regulationsrelating-to-the-commercial-use-of-small-drones/ (29 March 2019).

Csanyi, N., Toth, C.K., 2007. Improvement of lidar data accuracy using lidar-specific ground targets. Photogrammetric Engineering and Remote Sensing, 73(4), 385-396.

DJI, 2019. Matrice 600 Pro Specs. https://www.dji.com/uk/matrice600-pro/info [Accessed 02/04/2019]

Federal Emergency Management Agency, 2003. Guidelines and Specifications for Flood Hazard Mapping Partners, Appendix A: Guidance for Aerial Mapping and Surveying. https://www.fema.gov/media-library-data/1387814416677caa613eeca53246cb7a7dcbf342a7197/Guidelines+and+Specific ations+for+Flood+Hazard+Mapping+Partners + Appendix + AGuidance + for + Aerial+Mapping + and + Surveying $+($ Apr +2003$) . p$ df (3 March 2019).

Glira, P., Pfeifer, N., Mandlburger, G., 2016. Rigorous Strip Adjustment of UAV-based Laserscanning Data Including TimeDependent Correction of Trajectory Errors. Photogrammetric Engineering \& Remote Sensing, 82 (12), 945 - 954.

Lim, M., Mills, J. P., Barr, S. L., Barber, D., Glendinning, S., Parkin, G., Hall, J., Clarke, B., 2007. High Resolution Earth Imaging for Transport Corridor Slope Stability Risk Analysis. ISPRS Hannover Workshop 2007: High-Resolution Earth Imaging for Geospatial Information. Hanover. Institute of Photogrammetry and GeoInformation.

Mandlburger, G., Glira, P., Pfeifer, N., 2015. UAS-borne Lidar for Mapping Complex Terrain and Vegetation Structure. GIM International, 29(7), 30-33.
Pajares, G., 2015. Overview and Current Status of Remote Sensing Applications Based on Unmanned Aerial Vehicles (UAVs). Photogrammetric Engineering and Remote Sensing, 81(4), 281-330.

Pilarska, M., Ostrowski, W., Bakuła, K., Górski, K., Kurczyński, Z., 2016. The Potential of Light Laser Scanners Developed for Unmanned Aerial Vehicles - The Review and Accuracy. The International Archives of Photogrammetry, Remote Sensing and Spatial Information Sciences, v. XLII2/W2, 87-95.

RIEGL Laser Measurement Systems, 2018. RIEGL miniVUXIUAV.

http://www.riegl.com/uploads/tx_pxpriegldownloads/RIEGL_m iniVUX-1UAV_Datasheet_2019-03-07.pdf (March 2019).

Routescene, 2019. Accuracy. https://www.routescene.com/the3d-mapping-solution/accuracy/ (29 March 2019).

Toth, C., Jóźków, G., 2016. Remote sensing platforms and sensors: A survey. ISPRS Journal of Photogrammetry and Remote Sensing, 115, 22-36.

Toth, C., Paska, E., Brzezinska, D., 2008. Using road pavement markings as good control for lidar data. International Archives of Photogrammetry, Remote Sensing and Spatial Information Sciences, v. XXXVII Part B1, 189-196. 